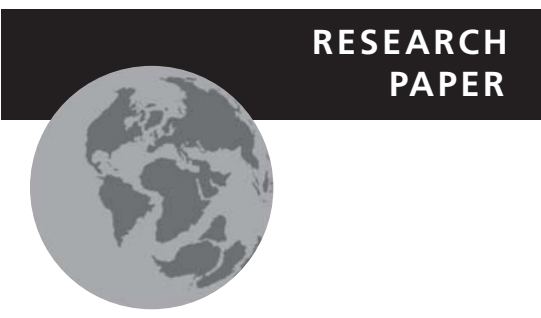

\title{
Forest structure determines the abundance and distribution of large lianas in Gabon
}

John R. Poulsen ${ }^{1 \star}$, Sally E. Koerner ${ }^{1}$, Zewei Miao ${ }^{1}$, Vincent P. Medjibe ${ }^{1}$, Ludovic Ngok Banak ${ }^{2}$ and L. J. T. White $e^{2,3,4}$

${ }^{1}$ Nicholas School of the Environment, Duke University, Durham, NC 27708, USA,

${ }^{2}$ Institut de Recherche en Ecologie Tropicale, Libreville, BP 13354, Gabon, ${ }^{3}$ Agence Nationale des Parcs Nationaux, Batterie IV, Libreville, BP 20379, Gabon, ${ }^{4}$ African Forest Ecology Group, School of Natural Sciences, University of Stirling, Stirling, UK
${ }^{*}$ Correspondence: John Poulsen, Nicholas School of the Environment, Duke University, PO Box 90328, Durham, NC 27708, USA. E-mail: john.poulsen@duke.edu

\section{ABSTRACT}

Aim Lianas are an important component of forest structure in the tropics, accounting for up to $45 \%$ of total stems. Mounting evidence that tropical forests are undergoing structural changes, with a growing abundance of lianas reducing forest carbon storage potential, imparts a sense of urgency to study the drivers that control liana abundance and biomass, particularly in Africa where data come from a few, small-scale studies.

Location Gabon, Africa.

Methods In the first countrywide study of lianas, we implemented the most ambitious, large-scale forest inventory in tropical Africa to date, quantifying the density, basal area and biomass of large lianas $(\geq 10 \mathrm{~cm}$ in diameter) using a systematic, random design of 104 plots located across Gabon. Additionally, we examined the relative importance of environmental variables (mean annual precipitation, mean annual temperature, seasonality, soil nitrogen, soil fertility), disturbance (effect of gaps, forest type) and forest structure (large tree biomass) in driving macroscale variation in the abundance of large lianas.

Results In total, we surveyed 1354 large lianas, and found the density, basal area and biomass of large lianas in Gabon to be comparable to that in other tropical forests. The success of large lianas was positively related to soil $\mathrm{N}$, but most strongly correlated with forest structure, particularly large tree biomass. The strength of the association between large lianas and large trees increased with tree size class.

Main conclusions Forest structure and the availability of large trees may be more important predictors of the abundance and distribution of large lianas in African tropical forests than environmental variables and disturbance. Changing environmental conditions are likely to have little direct effect on large lianas, but climate change, defaunation and land-use activities that diminish forest structure and reduce the number of large trees could have strong indirect effects on large lianas in Central African forests.

\section{Keywords}

Above-ground biomass (AGB), Central African forests, disturbance, forest characteristics, Gabon, large lianas, precipitation, seasonality, temperature. 


\section{INTRODUCTION}

Lianas are a key structural component of tropical forests and play a prominent role in forest-wide carbon sequestration, both directly and indirectly through competitive interactions with trees (Schnitzer \& Bongers, 2002; Duran et al., 2015). Woody vines commonly comprise $25 \%$ of the woody stems and species found in tropical forests (Schnitzer \& Bongers, 2002), and while lianas generally account for less than $10 \%$ of above-ground biomass (AGB) in mature tropical forests, they can contribute up to $30 \%$ in liana-dense areas (Putz, 1983; DeWalt \& Chave, 2004). Lianas also strongly influence forest structure by parasitizing trees and competing with them for below- and above-ground resources (van der Heijden \& Phillips, 2009; Schnitzer \& Bongers, 2011). As a result, liana density is often negatively correlated with tree biomass (Chave et al., 2001) and tree growth (Ladwig \& Meiners, 2009) and positively correlated with tree mortality (Ingwell et al., 2010). As the majority of carbon in tropical forests is stored in living tree biomass, increases in liana abundance are expected to decrease the carbon storage capacity of tropical forests (Duran et al., 2015).

Despite a growing recognition of the importance of lianas for carbon storage and forest ecology (Schnitzer et al., 2015), the vast majority of studies have focused on Neotropical and Southeast Asian forests (Bongers \& Ewango, 2015). Although Caballé's work in north-eastern Gabon shaped the early thinking on liana ecology (Caballe, 1984), Central African lianas remain largely unstudied compared with the other tropical regions. For example, Gentry's pantropical liana database includes just a few African sites (Gentry, 1991) and only c. $10 \%$ of liana studies occur in Central Africa. Of these studies, over half come from plots smaller than 1 ha (The Liana Ecology Map world database, http://www.lianaecologyproject.com/map). Even pantropical allometric equations for liana biomass lack data from African forests (Miao et al., 2016). Some evidence suggests that Palaeotropical forests, such as those of Central Africa, harbour lower densities of lianas than Neotropical forests (DeWalt et al., 2010) and that liana populations are not increasing in the Afrotropics as witnessed in the rest of the tropics (Caballe \& Martin, 2001; Bongers \& Ewango, 2015; Thomas et al., 2015). The richness, abundance and density of lianas vary greatly among forests and even within a single forest (Hegarty \& Caballe, 1991; Schnitzer \& Bongers, 2011), thus studies from one tropical region may not be generalizable to other regions.

Several hypotheses have been proposed to explain variations in liana distribution and abundance in relation to the physical environment. The first set of hypotheses deals with climate variables. Evidence suggests that liana abundance is negatively related to mean annual precipitation (MAP), positively related to mean annual temperature (MAT) and positively related to seasonality (Schnitzer, 2005; DeWalt et al., 2010; Duran et al., 2015). The ability to grow during the dry season when evapotranspirative demand is high is hypothesized to give lianas a competitive advantage over trees
(Schnitzer \& Bongers, 2011). Schnitzer (2005) found that lianas grew twice as fast as trees during the wet season, but seven times faster during the dry season. A second set of hypotheses focuses on resource availability. Increased levels of both $\mathrm{CO}_{2}$ and nitrogen might favour lianas over trees, as lianas are able to increase leaf nutrient levels, resulting in greater growth and photosynthetic capacity (Schnitzer \& Bongers, 2011; Laurance et al., 2014; Asner \& Martin, 2015). Several studies have found tropical lianas to grow rapidly under elevated $\mathrm{CO}_{2}$ conditions (Condon et al., 1992; Korner \& Arnone, 1992), but not faster than trees (Marvin et al., 2015). Limited testing of soil nitrogen has demonstrated only a weakly positive relationship (Gentry, 1991; Laurance et al., 2001) or no relationship (Dalling et al., 2012; Santiago et al., 2012; Ledo \& Schnitzer, 2014) with liana abundance.

Alternatively, liana distribution and abundance may be controlled by forest structure. Liana density is hypothesized to increase with greater levels of both natural disturbance, such as treefall gaps, and anthropogenic disturbance, such as logging (Putz, 1984; Dalling et al., 2012; Schnitzer et al., 2012; Ledo \& Schnitzer, 2014). Disturbance of the forest opens gaps, eventually producing patches of secondary forest: both of these habitats provide high-light environments and structural supports that facilitate abundant recruitment and rapid growth of lianas (Madeira et al., 2009). Along these lines, liana density has been found to correlate positively with small trees $(<10 \mathrm{~cm}$ in diameter; Nabe-Nielsen, 2001). On the other hand, anthropogenic disturbance characterized by high rates of liana cutting and tree removal may eliminate any positive effect for liana abundance (Addo-Fordjour et al., 2012). Some evidence suggests that disturbance might explain liana density, whereas liana basal area (BA) and AGB depend more strongly on other structural characteristics of the forest (van der Heijden \& Phillips, 2008). Large lianas use large trees as hosts to support their biomass and to gain access to the high-light conditions in the canopy (Phillips et al., 2005). Thus, forests with a low abundance of large trees may consequently have a low density and AGB of large lianas.

In this study, we quantify large lianas in Gabon using a network of 104 sites - the largest forest inventory in tropical Africa in recent times. By comparison, the most comprehensive examination of African forest structure to date employed just 260 plots for all of West, Central and East Africa, with just a handful of plots from Gabon (Lewis et al., 2013). In our study, the sampling sites were positioned in a systematic, random design, thereby capturing variability in climate, resources, disturbance and forest structure across the country. We focus on large lianas [diameter at breast height (d.b.h.) $\geq 10 \mathrm{~cm}$ ] that account for a major fraction of liana biomass and have the strongest effects on tree growth and mortality (see references in Phillips et al., 2005). We estimate countrywide metrics (density, BA, AGB) of large lianas, and test the relative importance of the physical environment versus forest structure in explaining the distribution of large lianas. To this end, we examine eight hypothesized drivers of large liana metrics. Based on previous studies from other tropical 


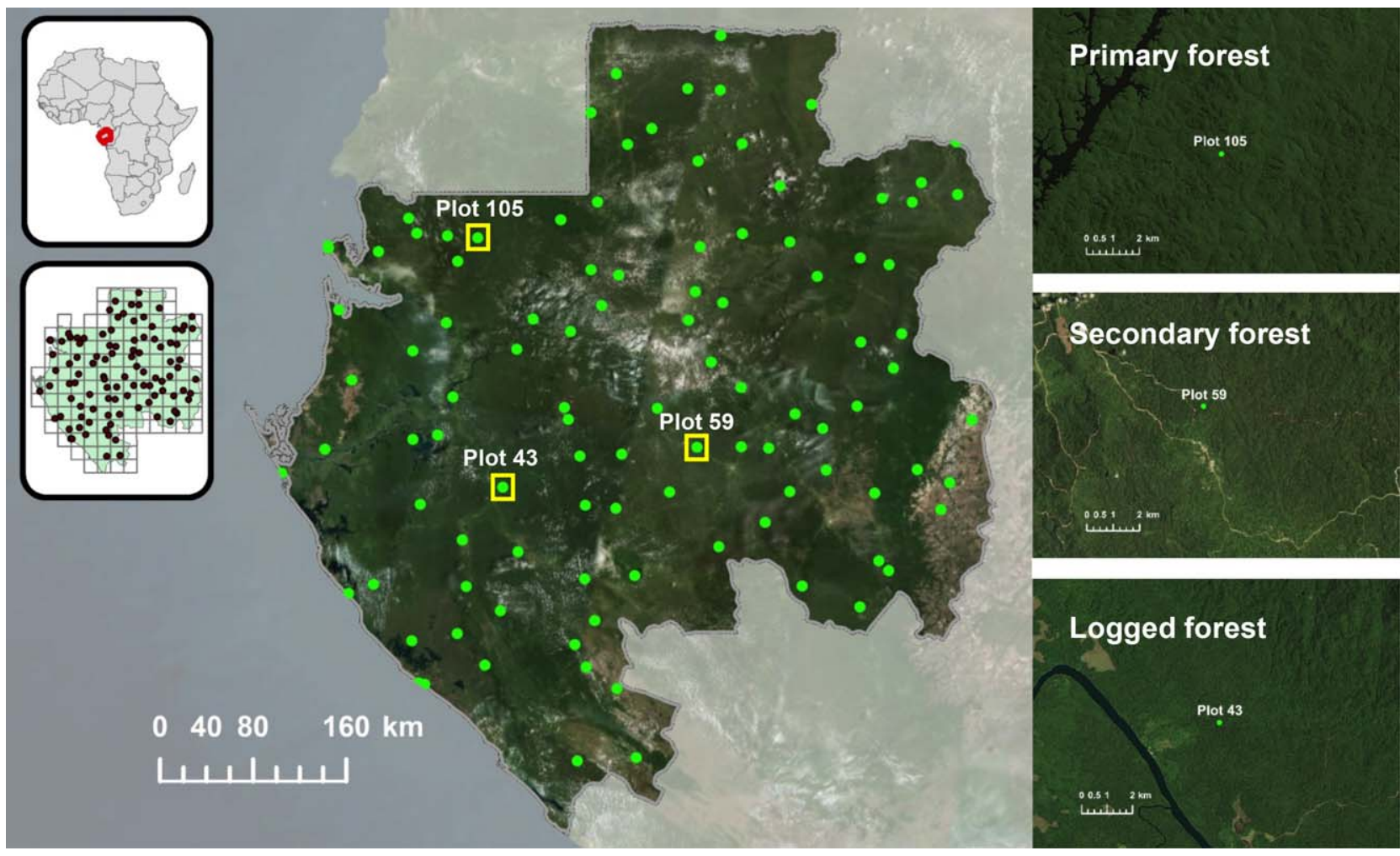

Figure 1 National resource inventory (NRI) sites in Gabon, with green points representing 1.64-ha (a single 1-ha plot and four 0.16-ha satellite plots) sampling plots for large lianas and trees. Inset maps show the location of Gabon within Africa and the $50 \mathrm{~km} \times 50 \mathrm{~km}$ grid used to locate NRI sites in a systematic, random manner. Panels on the right show sampling plots in primary, secondary and logged forest.

regions, we predict that large liana success will be: (1) negatively related to MAP, (2) positively related to MAT, (3) positively related to seasonality, $(4,5)$ positively related to soil resources (nitrogen and soil fertility), $(6,7)$ positively related to forest disturbance (i.e. treefall gaps and forest type logged, secondary, primary forest), and (8) positively related to tree density and biomass. This large-scale Central African liana dataset can provide insights into the factors that control liana success, much needed information for the prediction of the responses of lianas to future global change scenarios.

\section{MATERIAL AND METHODS}

\section{Study area \& monitoring design}

Gabon is the second most forested country in the world, with $88 \%$ of its area $\left(267,667 \mathrm{~km}^{2}\right)$ covered by tropical rain forest. With little spatial variation, the long-term (19902009) mean annual temperature of Gabon is $24.8^{\circ} \mathrm{C}$, reaching a high of $25.9^{\circ} \mathrm{C}$ between January and March and a low of $22.8^{\circ} \mathrm{C}$ between June and August. MAP $(1844.1 \mathrm{~mm})$ is seasonal with a dry season from June to August (3-month mean $29.1 \mathrm{~mm}$ ) and two peaks in precipitation between March to May (mean $201.5 \mathrm{~mm}$ ) and October to November (299.4 mm). MAP declines along an east-to-west gradient with a high of $3153 \mathrm{~mm}$ along the coast falling to $1366 \mathrm{~mm}$ in the south-west of the country. Variation in forest composition roughly overlies the precipitation gradient, with mesic equatorial coastal forests in the west transitioning to dryer Guinean-Congolian lowland forests in the east. Selective logging occurs in $31 \%$ of the forests with a harvest intensity of $0.4-0.8$ trees $\mathrm{ha}^{-1}$ that varies with logging technique and history (Medjibe et al., 2013). Secondary forests recovering from slash-and-burn agriculture or other forms of deforestation are generally found near towns and villages and along roads.

In 2012, the Government of Gabon initiated a national resource inventory (NRI), a network of field sites located in a systematic, random design to quantify and monitor its forest resources, with an initial focus on forest carbon (Fig. 1). The NRI currently consists of 104 sites, each comprising a single 1-ha $(100 \mathrm{~m} \times 100 \mathrm{~m})$ permanent plot and four 0.16ha $(40 \mathrm{~m} \times 40 \mathrm{~m})$ 'satellite' plots. Plots are positioned in a winged-design, with two 0.16 -ha plots located east of the permanent plot and two 0.16-ha plots located west of the permanent plot, and a distance of $250 \mathrm{~m}$ separating adjacent plots.

\section{Field measurements of lianas}

Four teams of five technicians from the Gabon Parks Agency (Agence Nationale des Parcs Nationaux, ANPN) inventoried the plots for large lianas and trees using standard protocols 
for forest plot establishment and measurement. The field technicians were all graduates of Gabon's National School of Forestry or experienced foresters and took part in a 2 month training on liana and tree inventory before the start of the study. The field teams established the inventory plots at preestablished GPS points, using RAINFOR methods to demarcate the plot boundaries, inventory and measure all lianas and trees with d.b.h. $\geq 10 \mathrm{~cm}$ (Phillips et al., 2009). All measured lianas and trees in the permanent plots, but not the satellite plots, were marked with individually numbered aluminium tags and mapped to the nearest metre. A quality control team led by V.P.M. remeasured approximately $20 \%$ of the plots, verifying the accuracy of plot delimitation and plant measurements. Data were processed and stored at the Gabon Parks Agency and double-checked for errors before analysis.

The field protocol consisted of counting and measuring large lianas if any part of the liana stem was rooted within a plot. When a liana had multiple root or stem sprouts, only the largest stem (diameter $\geq 10 \mathrm{~cm}$ ) was counted and measured. The field technicians measured any liana that reached $10 \mathrm{~cm}$ diameter at any point along the stem between $0 \mathrm{~m}$ (last rooting point) and $2.5 \mathrm{~m}$ above the ground. For each individual liana, the diameter was measured at three locations on the stem: (1) $D_{\text {passing, }}$ the stem diameter at $130 \mathrm{~cm}$ above the ground vertically, i.e. the d.b.h. above the ground regardless of distance from the roots; (2) $D_{130}$, the stem diameter at $130 \mathrm{~cm}$ along the stem from the last rooting point; and (3) $D_{\text {largest }}$, the stem diameter at the widest point on the stem within $2.5 \mathrm{~m}$ of the ground, including any deformities. For stems that were flat or elliptical rather than cylindrical, field technicians measured the diameter at the widest and narrowest points and calculated the geometric mean. We used all three methods of measurement to evaluate their consistency for estimating the density, BA and AGB of large lianas, but only report results from $D_{130}$ here.

\section{Basal area and above-ground biomass of large lianas}

From the field data, we calculated liana BA $\left(\mathrm{m}^{2} \mathrm{ha}^{-1}\right)$ as
$\mathrm{BA}=\frac{1}{A} \sum_{i=1}^{n} \pi\left(\frac{D_{i} / 2}{100}\right)^{2}$

where $D_{i}$ is the diameter of liana $i$ in $\mathrm{cm}$ from $D_{130}, D_{\text {passing }}$ or $D_{\text {largest }}, n$ is the number of large lianas at a site and $A$ is the total site area. We used the pantropical allometric equation to estimate individual liana AGB (kg dry mass/stem; Schnitzer et al., 2006):

AGB $=\exp \left[-1.484+2.657 \ln \left(D_{130}\right)\right]$.

We then summed the biomass of all individual stems at a site and divided by site area to derive stand-level AGB (Mg dry mass $\mathrm{ha}^{-1}$ ). We estimated the average large liana density, BA and AGB across the country, calculating 95\% bootstrap confidence intervals for each.

\section{Drivers of liana abundance}

To assess the independence of our sampling sites, we estimated the spatial autocorrelation in liana AGB among sites using Moran's index, $I$, calculated as:

$I=\frac{N}{\sum_{i} \Sigma_{j} w_{i j}} \frac{\sum_{i} \Sigma_{j} w_{i j}\left(\mathrm{AGB}_{i}-\overline{\mathrm{AGB}}\right)\left(\mathrm{AGB}_{j}-\overline{\mathrm{AGB}}\right)}{\sum_{i}\left(\mathrm{AGB}_{i}-\overline{\mathrm{AGB}}\right)^{2}}$

where $N$ is the number of spatial units (field sites), $\mathrm{AGB}_{i}$ and $\mathrm{AGB}_{j}$ are large liana biomass $\left(\mathrm{Mg}\right.$ dry mass $\mathrm{ha}^{-1}$ ) at sites $i$ and $j$ and $w_{i j}$ is an element of a matrix of spatial weights associated with distances between sites $i$ and $j$ (Getis \& Ord, 2010).

To identify the determinants of large liana community structure, we used simple and multiple linear regression models to evaluate the relationship between stem density, BA and $\mathrm{AGB}$ and their hypothesized drivers, including climate, resource availability, disturbance and tree AGB. We employed eight variables to represent the four categories (Table 1). For climate variables, we extracted MAP and MAT from the WorldClim database at the finest resolution available $\left(30^{\circ}\right)$ (Hijmans et al., 2005). We employed climatic water deficit (CWD), the water lost by the environment during dry

Table 1 Environmental variables, including their mean, standard deviation (SD) and range, used to explain the variation in large liana stem density, basal area and aboveground biomass.

\begin{tabular}{lll}
\hline Variables & Mean \pm SD & Range \\
\hline Mean annual temperature $\left({ }^{\circ} \mathrm{C}\right)$ & $24.6 \pm 1.0$ & $22.0-26.3$ \\
Mean annual precipitation $(\mathrm{mm})$ & $1882.0 \pm 332.4$ & $1366.0-3153.0$ \\
Climatic water deficit $(\mathrm{mm})$ & $-200.5 \pm 54.0$ & -323.5 to -78.8 \\
Soil nitrogen $\left(\mathrm{g} \mathrm{kg}^{-1}\right)$ & $1.6 \pm 0.5$ & $0.9-2.8$ \\
Base saturation (\%) & $47.2 \pm 10.1$ & $35.5-65.2$ \\
Forest type (primary, secondary, logged) & - & - \\
Presence of treefall gaps (none, minor, major) & - & - \\
Tree above-ground biomass $\left(\mathrm{Mg} \mathrm{ha}^{-1}\right)$ & $302.7 \pm 111.4$ & $52.4-554.0$ \\
\hline
\end{tabular}

Note that climatic water deficit is the difference between rainfall and evapotranspiration during dry months; thus, a value of 0 represents no seasonal water stress whereas very high negative values indicate strong seasonal water stress. 
months where evapotranspiration exceeds rainfall, as a measure of seasonality, downloading a global climate layer for the long-term average of CWD at 2.5-arcmin resolution (http://chave.ups-tlse.fr/pantropical_allometry.htm). For soil nutrients, we extracted information on topsoil $(0-20 \mathrm{~cm})$ nitrogen and base saturation (BS) at $30-\operatorname{arcsec}(1 \mathrm{~km}$ at the equator) resolution from the Harmonized World Soil Database (FAO/IIASA/ISRIC/ISS-CAS/JRC, 2009). We treat BS as an index of soil fertility as it expresses the percentage of soil occupied by basic cations ( $\mathrm{Ca}, \mathrm{Mg}, \mathrm{K}, \mathrm{Na}$ ): soils with high BS are generally more fertile because they have little or no $\mathrm{Al}^{3+}$ that is toxic to plant growth, have a higher $\mathrm{pH}$ and contain greater amounts of essential plant nutrient cations for use by plants. Interpretation of climate and soil characteristics should be treated with some caution, as these variables were not measured in situ. In the field, technicians recorded data on two different indicators of natural and human disturbance: presence of treefalls and forest type. Treefalls were classified by the diameter of the gap-creating tree, with a minor gap created by a tree $<40 \mathrm{~cm}$ d.b.h. and a major gap created by a tree $\geq 40 \mathrm{~cm}$ d.b.h. We assume that the large size category represents a canopy tree that would leave a hole in the emergent layer, whereas the small size category is likely to leave a space only in the canopy or understorey layers. The forest type for each field site was categorized as primary forest, logged forest and secondary forest. For stand structure, we used measurements of trees $(\geq 10 \mathrm{~cm} \mathrm{d.b.h.)} \mathrm{col-}$ lected concomitantly with the large liana survey to calculate tree AGB and density for each field site.

We first fitted simple linear regressions to evaluate the independent effects of climate, soil, disturbance and tree AGB variables on the three liana metrics. After examining residuals of simple linear regressions, we log transformed all response variables to satisfy the assumptions of normality and homoscedasticity. We then developed a full model with all possible variables and eliminated non-significant predictor variables $(P>0.10)$ through backward stepwise selection to find the most parsimonious model. For both bivariate and multivariate models we included second-order terms (i.e. $\mathrm{CWD}^{2}, \mathrm{AGB}_{\text {tree }}^{2}$ ) to accommodate apparent unimodal relationships between the predictor variables of CWD and tree AGB and the response variables. To examine the relative importance of each parameter in the final model, we partitioned the total variation in the response variable. All data processing and statistical analyses were performed with $\mathrm{R}$ statistical software (The R Foundation for Statistical Computing, version 3.1.0).

\section{RESULTS}

\section{Gabon large liana characteristics}

Across the 104 sites, we recorded 1354 large lianas, with lianas occurring in 30 secondary forest sites, 26 logged forest sites and 43 primary forest sites. Five sites located either in mangrove or secondary forest did not contain large lianas. Mean liana diameter, stem density, $\mathrm{BA}$ and $\mathrm{AGB}$ varied strongly across sites (Fig. 2). Liana diameter $\left(D_{130}\right)$ varied from 10 to $36.5 \mathrm{~cm}$ (mean $13.7 \pm 3.9 \mathrm{~cm}$ ). On average across the 99 plots containing large lianas, we found $10.2 \pm 6.8$ ( \pm $1 \mathrm{SD}$ ) liana stems ha ${ }^{-1}$ (range 1-39 stems ha ${ }^{-1}$ ), with mean individual liana BA of $144.0 \pm 100 \mathrm{~cm}^{2}$ per stem and mean liana AGB of $2.5 \pm 2.0 \mathrm{Mg} \mathrm{ha}^{-1}$ (95\% CI 2.4-7.1 $\mathrm{Mg} \mathrm{ha}^{-1}$; Fig. 3). Large liana density (stems $\mathrm{ha}^{-1}$ ) in a site was significantly correlated with large liana AGB $\left(R^{2}=0.69\right.$, $F_{1,97}=215.4, P<0.001$; Fig. 2d). Generally, large liana AGB was lower in the estuary mangrove coastal forest, southwestern savanna mosaics and south-eastern mountain areas (highest elevation $752 \mathrm{~m}$ ). Large liana AGB accounted for $0.84 \pm 0.75 \%$ (95\% CI $0.09-5.20 \%$ ) of total AGB (including large trees and lianas, but not litter or necromass).

\section{Drivers of liana abundance}

We found no evidence of significant spatial autocorrelation among the sites for large liana stem density $(I=0.004$, $\mathrm{SD}=0.01, P=0.310)$, BA $(I=-0.008, \mathrm{SD}=0.01, P=0.882)$ and AGB $(I=-0.008, \mathrm{SD}=0.01, P=0.868)$. Therefore, we treated sites as independent replicates and regressed liana density, BA and AGB with abiotic environmental and disturbance variables.

Using simple linear regression, we found large liana density, BA and AGB to be significantly positively related to topsoil $\mathrm{N}$ and tree AGB (Figs 3-5). There were no significant relationships between large liana metrics and MAP, MAT, CWD, BS or effect of treefall. Because of the high variation in large liana density, BA and AGB at low precipitation levels compared with high precipitation levels (Figs 3-5), we also regressed the response variables against MAP for sites with $<2100 \mathrm{~mm}$ and $\geq 2100 \mathrm{~mm}$ of rainfall: in all cases, large lianas were not significantly related to MAP (Figs 3-5).

The only evidence that large lianas were positively related to disturbance was a marginally significant difference in liana density across forest types $\left(F_{2,96}=2.295, P=0.106\right)$, with secondary forest having marginally lower large liana densities than primary forests (Tukey post-hoc test, $P=0.089$ ). Although large liana BA and AGB were also lowest in secondary forest, they did not vary significantly among forest types (Figs 3-5). To further explore the potential effects of disturbance on large lianas, we assessed the relationship among large liana metrics and general characteristics of disturbed forest, including high tree density, low tree BA and low wood density (van der Heijden \& Phillips, 2008). Large liana density was positively related to tree density $(r=0.22$, $P=0.025)$, tree BA $(r=0.21, P=0.038)$ and wood density ( $r=0.25, P=0.012$ ), characteristics more strongly associated with old-growth forests than disturbed forests. Large liana BA and AGB showed similar results; thus there is very little evidence that large lianas are associated with disturbance in Gabon.

Using multiple linear regression to evaluate the effects of climate, resource availability, disturbance and forest structure on large lianas, we found liana metrics to be significantly 

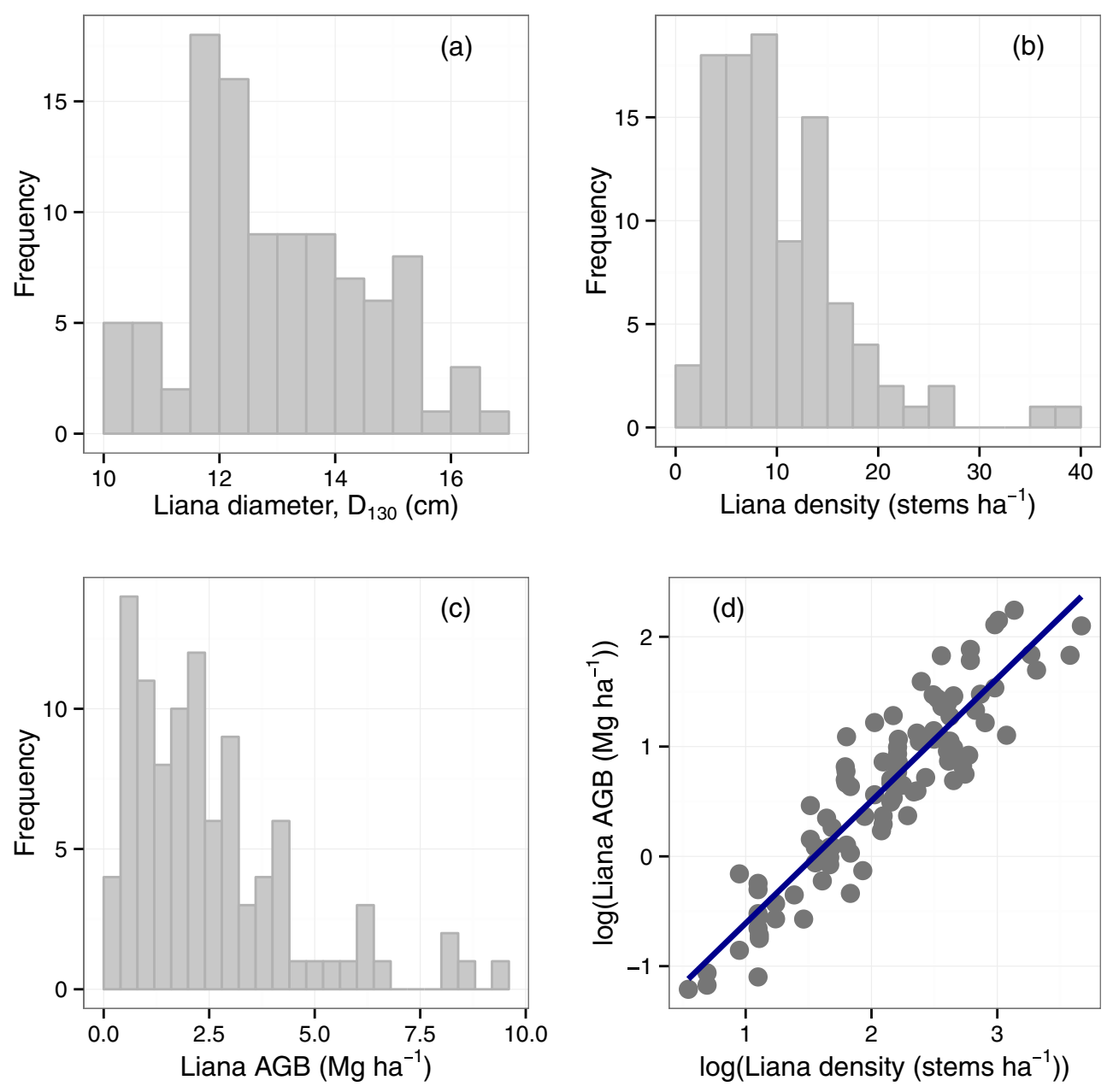

Figure 2 Characteristics of large lianas from the 104 inventory sites in Gabon, including: (a) distribution of mean diameter, $D_{130}$ (cm); (b) distribution of stem density ( stems ha ${ }^{-1}$ ); (c) distribution of aboveground biomass (AGB; Mg $\mathrm{ha}^{-1}$ ); and (d) the relationship between density (stems ha ${ }^{-1}$ ) and AGB ( $\left.\mathrm{Mg} \mathrm{ha}^{-1}\right)$ : $\log (\mathrm{AGB})_{\mathrm{L}}=1.64+0.743$ $\times \log (\mathrm{LD})\left(F_{1,97}=469.7\right.$, $\left.R^{2}=0.83, p<0.001\right)$.

and positively related to soil nitrogen and tree AGB (Table 2). In all cases, the relationship between large lianas and tree AGB was unimodal, with liana density, BA and AGB decreasing at very high levels of tree AGB. Large liana density was also marginally negatively related to MAP and the presence of treefall gaps, with the presence of minor and major gaps having non-significant positive and negative effects on large lianas compared with plots with no treefall gaps (Table 2).

To verify that the positive effect of tree AGB on large lianas was not driven by disturbed forest, we re-ran the models with data from only primary forest (excluding secondary and logged forest sites). Both the best-fitting models and the effect sizes of the coefficients were nearly the same as those for the entire dataset (Appendix S2), except that MAP had a significant negative effect on all large liana metrics. The key point is that tree AGB was retained in these models.

Given the importance of tree AGB in our models, we evaluated the relationship between large liana metrics and the number of trees of four different d.b.h. size classes (Fig. 6 and Fig. S1 in the Supporting Information). The effect of tree numbers on large liana AGB increased with tree size. Bigger forests, those with greater numbers of large trees, supported a higher density of large lianas, higher BA and higher AGB (Fig. S2). With each additional small tree (10-20 cm d.b.h.), large liana AGB increases by $0.1 \%$, whereas each additional large tree $(>60 \mathrm{~cm}$ d.b.h.) increases large liana AGB by $3.0 \%$. We found similar relationships between large liana density and BA and tree size (Fig. S2).

\section{DISCUSSION}

To our knowledge, this is the first study to assess large liana density, BA and AGB across an entire tropical country, and the largest dataset to date (in terms of the number of sampling sites and lianas) from the Afrotropics. Using a systematic random design of 104 plots across Gabon, we surveyed 1354 large lianas $(\geq 10 \mathrm{~cm}$ in diameter) and found that the density and AGB of large lianas were comparable to other tropical forests. Contrary to our hypotheses, large lianas in Gabon did not respond strongly to climatic drivers or disturbance; instead large liana metrics were correlated with soil $\mathrm{N}$ and tree AGB (van der Heijden \& Phillips, 2008). As the number of large trees increases in a forest in Gabon, the density, BA and AGB of large lianas increases, suggesting that large trees play an important role in the structural support of large lianas. 

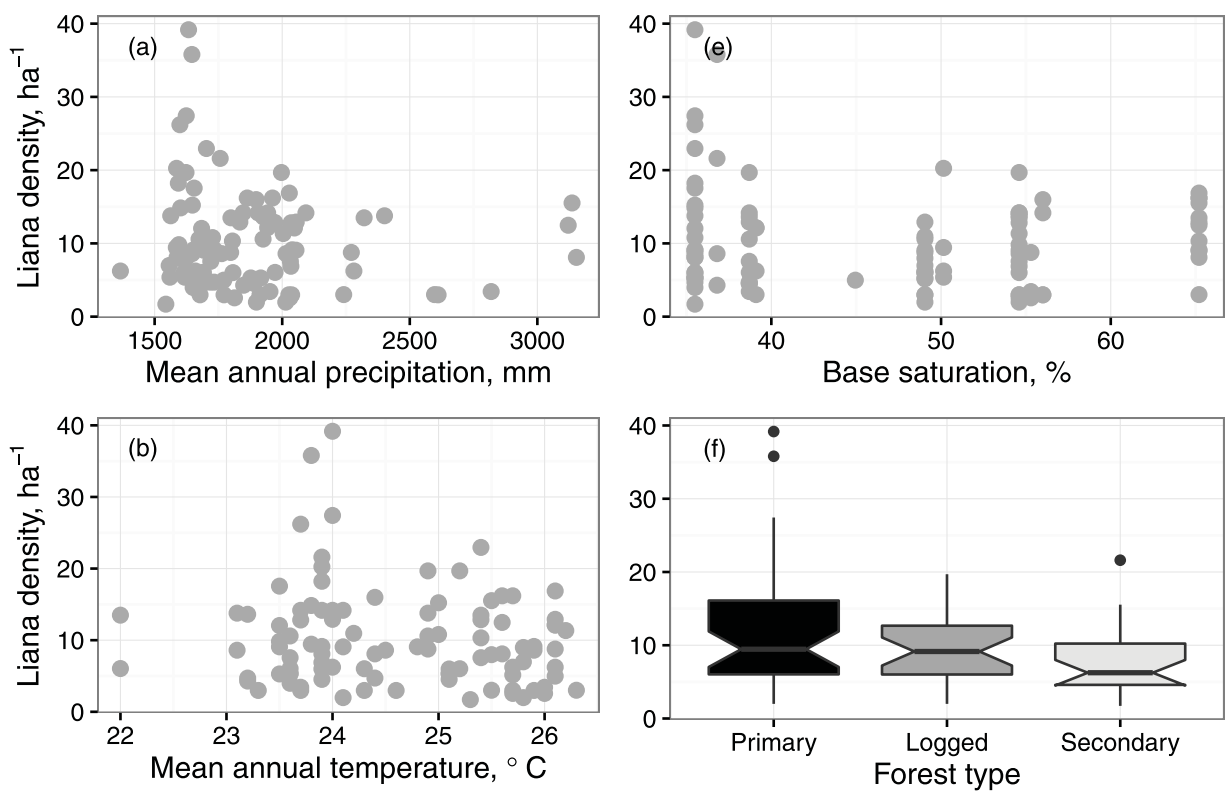

Figure 3 Relationship between large liana density and hypothesized drivers of liana distribution and abundance, including: (a) mean annual precipitation, (b) mean annual temperature, (c) climatic water deficit, (d) soil nitrogen, (e) base saturation, (f) forest type, (g) effect of treefall gaps, and $(\mathrm{h})$ tree above-ground biomass (AGB) (Table 1). Regression lines depict bivariate relationships for statistically significant variables; scatter plots without regression lines depict non-significant bivariate relationships.
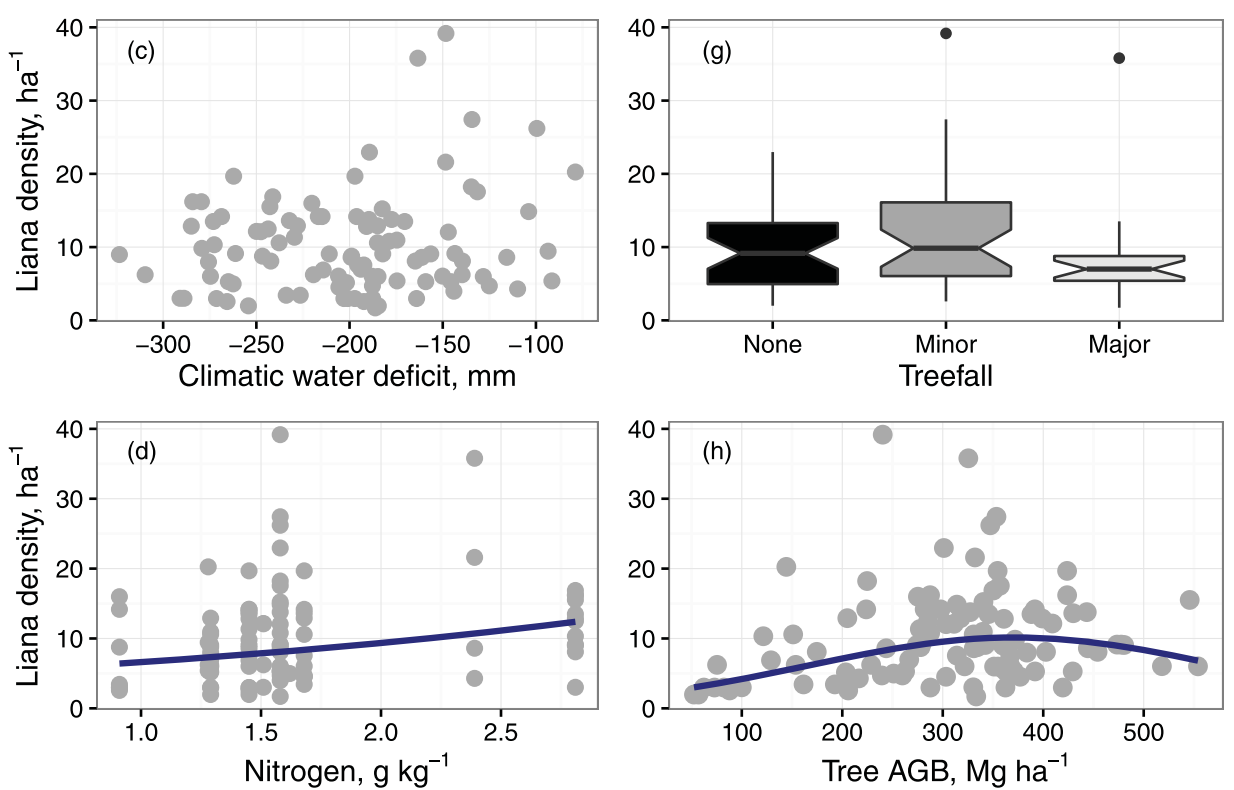

\section{Large liana density and AGB}

Liana populations ( $\geq 2.5 \mathrm{~cm}$ d.b.h.) have been hypothesized to be more (Gentry, 1991; Schnitzer \& Bongers, 2002), less (DeWalt et al., 2010) and equally abundant (DeWalt et al., 2015) in the Neotropics and Afrotropics. While we do not have data for lianas in smaller size classes, we found the mean densities of large lianas (10.2 stems ha ${ }^{-1}$, range 1-39 stems $\mathrm{ha}^{-1}$ ) in Gabon to be comparable to other regions. For comparison, forests support 12.6 large stems ha ${ }^{-1}$ in south-eastern Peru (Phillips et al., 2005) and 10 large stems $\mathrm{ha}^{-1}$ in Panama (Schnitzer et al., 2012). In French Guiana, large liana densities reach 15.3, 24, 21 and 10 stems ha $^{-1}$ (Schnitzer et al., 2006; Chave et al., 2008), but the two studies that found $>20$ stems ha ${ }^{-1}$ occurred at sites with high levels of disturbance. In Africa, large liana density is 10 stems $\mathrm{ha}^{-1}$ in Cameroon (Thomas et al., 2015) and 13.5 and 8.3 stems $\mathrm{ha}^{-1}$ at two separate sites in the Democratic Republic of Congo (Ewango, 2010; Bongers \& Ewango, 2015). Densities of large lianas in the Afrotropics, therefore, appear to be similar to those in other tropical regions.

Large liana AGB in Gabon was also similar to other tropical regions, with an average biomass of $2.5 \pm 2.0 \mathrm{Mg}$ $\mathrm{ha}^{-1}$ over the 99 plots that contained lianas. Liana AGB ranged from 0.2 to $9.4 \mathrm{Mg}$ dry matter $\mathrm{ha}^{-1}$, with the highest levels in the north-eastern primary forests and western coastal areas of Gabon. In French Guiana, large liana AGB in two plots over two census periods ranged from 4.8 to $10.2 \mathrm{Mg} \mathrm{ha}^{-1}$ (Chave et al., 2008). Few other studies report large liana AGB, probably because of the known shortcomings of existing allometric equations (Chave et al., 2008; Miao et al., 2016). But with the recognition that tropical forests contribute to mitigation of climate change 

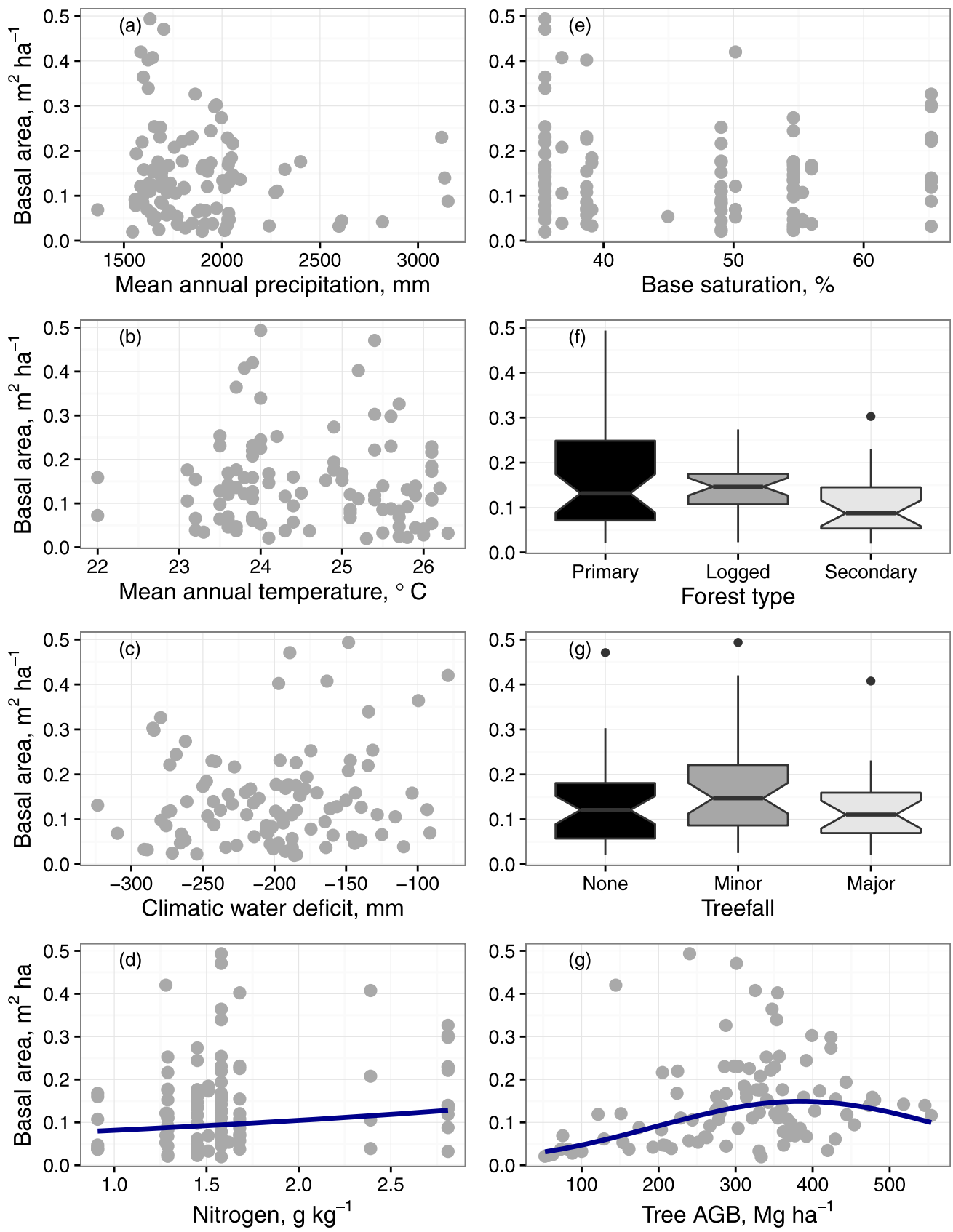

Figure 4 Relationship between large liana basal area (BA) and hypothesized drivers of liana distribution and abundance, including: (a) mean annual precipitation, (b) mean annual temperature, (c) climatic water deficit, (d) soil nitrogen, (e) base saturation, (f) forest type, (g) effect of treefall gaps, and (h) tree above-ground biomass (AGB) (Table 1). Regression lines depict bivariate relationships for statistically significant variables; scatter plots without regression lines depict non-significant bivariate relationships.

through carbon storage and sequestration, efforts to monitor tropical forest carbon stocks are expanding (Maniatis \& Mollicone, 2010). Forest monitoring usually focuses on large plant life-forms (trees and lianas $\geq 10 \mathrm{~cm}$ d.b.h.; e.g. Phillips et al., 2009), which may make estimates of large liana AGB more commonplace and more valuable for cross-site comparisons in the future. In Gabon, large lianas comprise a very small fraction of forest carbon, although their importance could grow if lianas increase in abundance relative to trees (Schnitzer \& Bongers, 2011; Schnitzer et al., 2012).

\section{Environmental drivers of liana density, BA and AGB}

In contrast to our results, multiple studies have shown that liana abundance, BA and AGB increase with decreasing MAP and increasing MAT (Schnitzer, 2005; DeWalt et al., 2010; Duran et al., 2015). While our sites do not span a wide range 

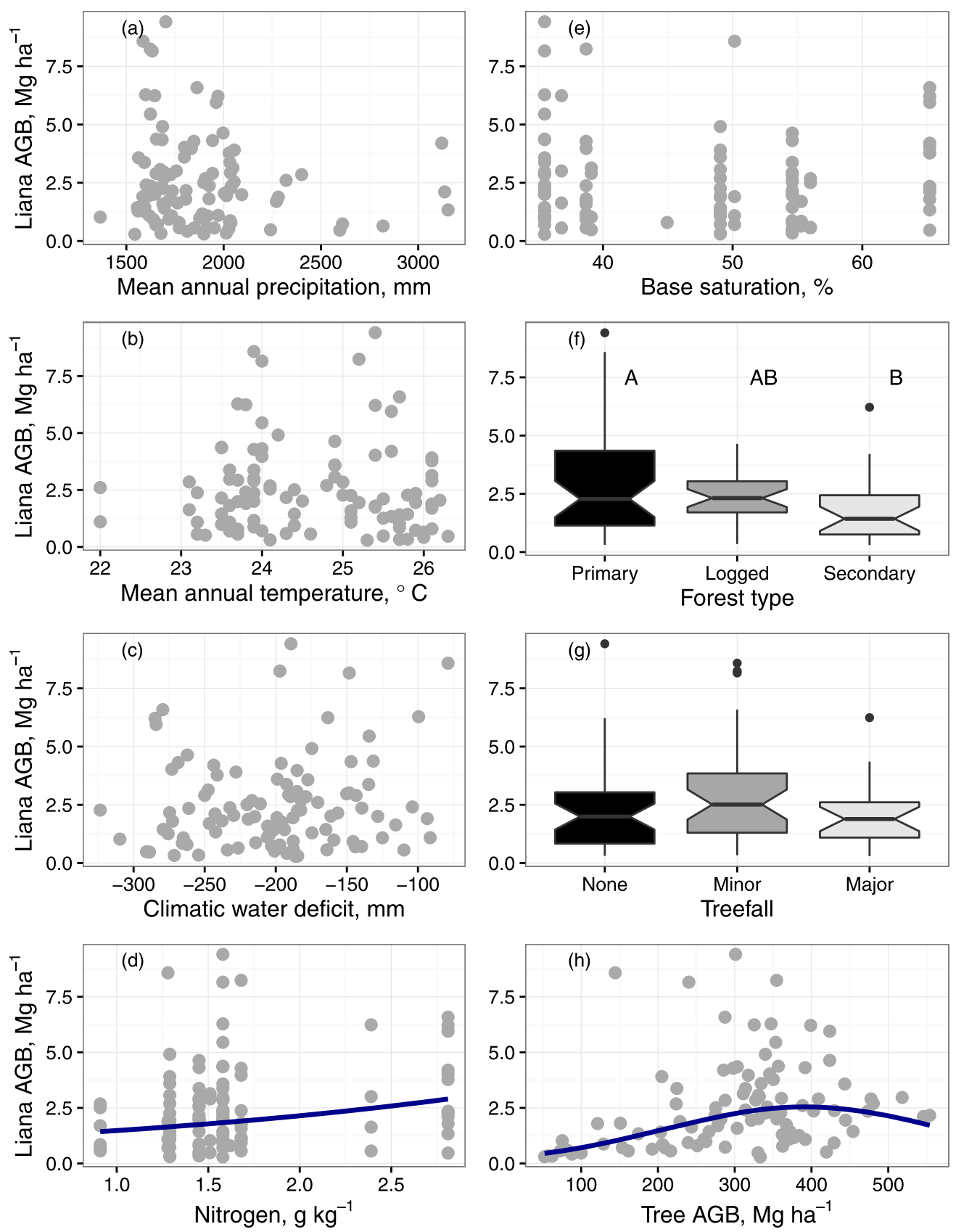

Figure 5 Relationship between large liana above-ground biomass (AGB) and hypothesized drivers of liana distribution and abundance, including: (a) mean annual precipitation (MAP), (b) mean annual temperature, (c) climatic water deficit, (d) soil nitrogen, (e) base saturation, (f) forest type, (g) effect of treefall gaps, and (h) tree AGB (Table 1). Regression lines depict bivariate relationships for statistically significant variables; scatter plots without regression lines depict non-significant bivariate relationships. Note that there also was no significant relationship between large liana AGB and MAP at sites with $<2100 \mathrm{~mm}$ MAP $\left(F=0.320\right.$, d.f. $=86, R^{2}=0.004$, $P=0.573)$ and $\geq 2100 \mathrm{~mm}\left(F=0.312\right.$, d.f. $\left.=9, R^{2}=0.034, P=0.590\right)$.

of temperatures, they do cover a MAP gradient of roughly 1400-3000 mm, the range over which lianas were most sensitive to precipitation in a global study (DeWalt et al., 2015). Thus, if precipitation strongly influences the abundance of large lianas in Gabon, we should have detected it. Seasonality is also hypothesized to drive liana abundance by conferring a competitive advantage to lianas over trees during the dry season, when light and temperature are relatively high (Schnitzer \& Bongers, 2011). High evapotranspirative demand can force trees to go dormant, whereas lianas can continue to grow over the dry season (Schnitzer, 2005). However, seasonality did not strongly influence large liana metrics in Gabon. Constant cloud cover over the country during the main dry season keeps temperatures low relative 


\section{J. R. Poulsen et al.}

Table 2 Results of final, reduced multiple linear regression models evaluating the relationship between large liana density, basal area (BA) and above-ground biomass (AGB) and eight predictor variables: climate [mean annual precipitation (MAP) (mm); mean annual temperature (MAT) $\left({ }^{\circ} \mathrm{C}\right)$; climatic water deficit (CWD) (mm)]; soil nutrient availability (soil nitrogen, $\left.\mathrm{N}_{\text {soil }}\right)\left(\mathrm{g} \mathrm{kg}^{-1}\right)$; base saturation, BS (\%); disturbance (treefall gaps and forest type); and tree AGB $\left(\mathrm{Mg} \mathrm{ha}^{-1}\right)$. Treefall gaps (none, minor, major) and forest type (primary, logged, secondary) are categorical variables, whereas all other predictors are continuous variables.

\begin{tabular}{|c|c|c|c|c|c|}
\hline Variable & $\beta$ & SE & $F$ or $t$ & $p$ & $R^{2}$ \\
\hline Liana density & & & $F_{6,92}=9.03$ & $<0.001$ & 0.274 \\
\hline Intercept & 0.731 & 0.468 & 1.561 & 0.122 & \\
\hline MAP & $-3.08 \times 10^{-4}$ & $1.85 \times 10^{-4}$ & -1.667 & 0.099 & 0.016 \\
\hline $\mathrm{N}_{\text {soil }}$ & 0.343 & 0.120 & 2.860 & 0.005 & 0.062 \\
\hline Treefall gap & & & & & 0.034 \\
\hline Minor & 0.114 & 0.130 & 0.870 & 0.387 & \\
\hline Major & -0.240 & 0.159 & -1.505 & 0.136 & \\
\hline Tree AGB & 0.009 & 0.002 & 4.229 & $<0.001$ & 0.126 \\
\hline Tree AGB $^{2}$ & $-1.21 \times 10^{-5}$ & $2.08 \times 10^{-6}$ & -3.419 & $<0.001$ & 0.076 \\
\hline Liana basal area & & & $F_{3,95}=14.5$ & $<0.001$ & 0.292 \\
\hline Intercept & -4.422 & 0.373 & -11.851 & $<0.001$ & \\
\hline $\mathrm{N}_{\text {soil }}$ & 0.281 & 0.127 & 2.221 & 0.029 & 0.042 \\
\hline Tree AGB & 0.011 & 0.002 & 4.776 & $<0.001$ & 0.170 \\
\hline Tree $\mathrm{AGB}^{2}$ & $-1.45 \times 10^{-5}$ & $3.89 \times 10^{-6}$ & -3.711 & $<0.001$ & 0.102 \\
\hline Liana AGB & & & $F_{3,95}=14.73$ & $<0.001$ & 0.296 \\
\hline Intercept & -1.791 & 0.405 & -4.418 & $<0.001$ & \\
\hline $\mathrm{N}_{\text {soil }}$ & 0.287 & 0.138 & 2.084 & 0.040 & 0.038 \\
\hline Tree AGB & 0.017 & 0.002 & 4.728 & $<0.001$ & 0.174 \\
\hline Tree $\mathrm{AGB}^{2}$ & $-1.52 \times 10^{-5}$ & $4.23 \times 10^{-6}$ & -3.606 & $<0.001$ & 0.105 \\
\hline
\end{tabular}

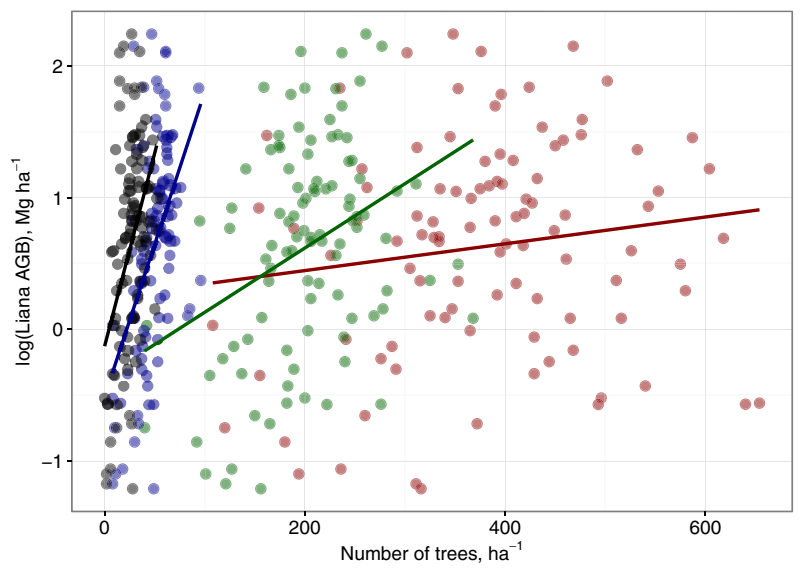

Figure 6 Evaluation of the effect of tree size (d.b.h.) on large liana above-ground biomass (AGB) in Gabon, by fitting linear regressions of log-transformed large liana AGB versus the number of trees ha ${ }^{-1}$ for four d.b.h. classes: red points $(<$ $20 \mathrm{~cm}$ d.b.h, $\left.F_{1,97}=2.057, R^{2}=0.011, P=0.154\right)$, green points (20 to $<40 \mathrm{~cm}$ d.b.h., $F_{1,97}=13.20, R^{2}=0.111, P<0.001$ ), blue points (40 to $<60 \mathrm{~cm}$ d.b.h., $F_{1,97}=31.98, R^{2}=0.240$,

$P<0.001)$, and black points ( $\geq 60 \mathrm{~cm}$ d.b.h., $F_{1,97}=22.26$,

$\left.R^{2}=0.178, P<0.001\right)$. There is a plot of the same regression but with no transformation of the $y$-axis in Fig. S1. Analyses of liana density and basal area demonstrated similar relationships

(Fig. S2). to the rest of the year (Saint-Vil, 1977). Thus, Gabon's relatively cool dry season might keep evapotranspiration low and attenuate any competitive advantage of lianas over trees for water.

Our study identified soil nitrogen as one of the principal determinants of the success of large lianas in Gabon, suggesting that nutrient limitation can influence liana density, BA and AGB. Although several studies of liana abundance have found weak (Gentry, 1991; Laurance et al., 2001) or no effects of nutrients on liana abundance (e.g. van der Heijden \& Phillips, 2008; Dalling et al., 2012; Santiago et al., 2012; Ledo \& Schnitzer, 2014), other studies demonstrate that the abundance of canopy-level lianas often increases with soil fertility (e.g. Putz, 1984; Putz \& Chai, 1987; Laurance et al., 2001; DeWalt et al., 2006). Recent studies of leaf traits place lianas at the quickreturn end of the leaf economics spectrum (Wright et al., 2004) and demonstrate that lianas have high foliar nutrient concentrations and high nutrient-use efficiency (including photosynthetic $\mathrm{N}$ ), giving them a competitive advantage over trees (Zhu \& Cao, 2010; Asner \& Martin, 2015). Interestingly, nutrient addition (including $\mathrm{N}$ ) does not disproportionately favour lianas, because lianas already outperform trees (Pasquini et al., 2015). We relied on a gridded global database of soils rather than in situ samples, so our estimates of soil $\mathrm{N}$ and nutrient cations are coarse at best. Fieldwork with simultaneous sampling of soils and lianas should be conducted to evaluate whether additional soil nutrients or characteristics determine the distribution and abundance of large lianas. 


\section{Disturbance and liana density, BA and AGB}

With few exceptions, lianas are fast-growing, light-limited plants associated with disturbed habitats, including forest edges, canopy gaps, secondary and logged forests. We therefore expected large lianas in Gabon to be positively related to disturbance, as reflected by forest type and the presence of gaps. Instead, we found little to no evidence that disturbance affects large liana metrics. Large liana density, BA and AGB tended to be lower in secondary forests than logged and primary forests (contrary to predictions), but not significantly so, and we did not find a strong effect of the presence of treefall gaps on large lianas. The evidence for higher liana loads in disturbed versus undisturbed forests comes largely from abundances of small lianas (e.g. Putz, 1984; Addo-Fordjour et al., 2013). Detecting an effect of disturbance on large lianas may be complicated by their relatively low abundance (c. 10 lianas $\mathrm{ha}^{-1}$ ) and variation compared with small lianas, which can reach abundances of 76-1414 lianas ha ${ }^{-1}$ (DeWalt et al., 2015).

There is no reason to suspect that Central African lianas function differently from lianas in other forests; thus, the failure to detect an effect of disturbance might lie in our indices of disturbance or the type of disturbance regimes found in Gabon. On one hand, our categorization of treefall gaps at the plot level was probably too coarse to detect variation in large lianas, and future studies should use more quantitative measures (i.e. the number or area of gaps). On the other hand, large liana abundance may not differ across forest types because there has been little recent or intense disturbance. Selective logging in Gabon targets a few valuable timber species so that harvest rates (and disturbance) tend to be low (Medjibe et al., 2011); thus the similarity in liana metrics between logged and old-growth forests is not surprising. Secondary forests in Gabon are generally found near rural villages created decades ago when colonial authorities relocated rural populations from the forest to major roads (cited in Oslisly et al., 2013). By comparison, the recent deforestation rate was $0.0034 \%$ from 1990 to 2000 and not distinguishable from zero between 2000 and 2010 (Sannier et al., 2014). We hypothesize that secondary forests have similar liana loads to other forest types because: (1) most secondary forests are decades old and transitioning into later-stage forests with turnover of pioneer species, and (2) rural people near villages reduce large lianas through smallscale disturbance (liana cutting and felling of host trees) (Addo-Fordjour et al., 2012). However, our study supports several studies from Africa and Asia, but not the Neotropics, showing a negative effect of disturbance on liana abundance (Caballe \& Martin, 2001; Chittibabu \& Parthasarathy, 2001; Addo-Fordjour et al., 2009; Schnitzer \& Bongers, 2011; AddoFordjour et al., 2012), suggesting that additional research is necessary to assess how regional variation in disturbance influences the success of lianas.

\section{Forest structure and liana density, BA and AGB}

In Gabon, structural characteristics of the forest explain more of the variation in large liana density, BA and AGB than the physical environment (climate, soils), similar to findings in the Neotropics (lianas $\geq 2.5 \mathrm{~cm}$ d.b.h.; van der Heijden \& Phillips, 2008). Of all the hypothesized determinants, tree AGB was the most important predictor of large lianas. One explanation for this pattern is that large lianas depend on the structural support provided by large trees. Lianas need host trees to reach the high-light environment in the canopy where they expand in diameter and invest in leaves and reproductive organs (Putz, 1995), and large lianas need large trees to support their biomass and provide access to the canopy (Phillips et al., 2005). An alternative, nonmutually exclusive explanation is that large lianas and large trees are facilitated by common environmental variables. However, we detected only weak associations between environmental variables and large lianas in Gabon (similar to van der Heijden \& Phillips 2008). Moreover, in contrast to our results, a recent study of large trees $(\geq 70 \mathrm{~cm}$ d.b.h.) in tropical forests found: (1) a strong positive correlation between large tree AGB and annual rainfall [liana metrics were unrelated (all plots) or negatively related (primary forest; Appendix S2) to precipitation]; and (2) a strong negative correlation between soil fertility and African trees (liana metrics were positively related to $\mathrm{N}$, and unrelated to soil fertility) (Slik et al., 2013).

In our study, large liana metrics were unimodally related to forest AGB, decreasing at a mean tree AGB of approximately $400 \mathrm{Mg} \mathrm{ha}^{-1}$. This pattern may simply be due to the small number of forest plots that exceed c. $450 \mathrm{Mg} \mathrm{ha}^{-1}$ (Figs 3-5). Two of the high-AGB plots occurred in mountainous terrain for Gabon, which would be consistent with the known drop-off in large liana density with increasing elevation in the tropics (Gentry, 1991). To our knowledge, there is no inherent reason why large lianas would decrease at a forest AGB of $400 \mathrm{Mg} \mathrm{ha}^{-1}$, unless trees have surpassed the maximum diameter that lianas can encircle (Putz, 1984; Putz \& Chai, 1987; Nabe-Nielsen, 2001). This pattern merits further research.

\section{Large lianas and large trees}

Large lianas may be characteristic of old-growth forests in Gabon, as large liana load increases with the number and size of large trees and is correlated with plot-level tree BA and wood density. While our country-level survey revealed intriguing patterns of liana abundance and distribution, long-term monitoring and experimentation is necessary to disentangle the interactions between large lianas and large trees, particularly in the face of the increasing dominance of lianas through much of the tropics (Schnitzer \& Bongers, 2011). Ironically, large lianas depend on large trees for structural support, but often suppress host growth (Clark \& Clark, 1990) and are associated with elevated risk of death for large trees (Phillips et al., 2005). If large lianas directly shorten the life expectancy of host trees, then tree species composition might be expected to shift towards fast-growing species with low wood density that are less likely to be 
infested by lianas, decreasing the carbon storage potential of the forest (van der Heijden \& Phillips, 2009). If large trees in Gabon are adapted to large lianas, then the greater availability of atmospheric $\mathrm{CO}_{2}$ from climate change might be expected to increase the availability of large trees (Lewis et al., 2009) (but see van der Sleen et al., 2015), and consequently, the number of large lianas - increasing the carbon storage potential of the forest. In either case, land-use activities such as industrial logging and agriculture that extract large trees and convert forest into plantation are having the most immediate effects on Central African forests, imperilling both large trees and large lianas (e.g. Medjibe et al., 2011; Burton et al., 2016). The future of large lianas and trees is interrelated: our study highlights the need to better understand large liana-tree dynamics in Central Africa and across the tropics to predict future effects arising from global change.

\section{ACKNOWLEDGEMENTS}

We thank C. Clark, P. Heine, C. Nunez, D. Richter, S. Schnitzer, J. Chave and two anonymous referees for helpful discussions and comments on the manuscript, and S. Moore for help with GIS and mapmaking. The Gabon National Climate Change Council authorized the establishment of the National Resource Inventory, which was supported financially by OLAM-Gabon and the US SilvaCarbon Program. The National Center for Scientific Research and Technology (CENAREST) provided permission to conduct this work, and the Gabon Parks Agency (ANPN) implemented the project. Special thanks to P. Nguema, C. Tayo, and the ANPN field team for their contributions to project implementation. The authors have no conflicts of interest to declare.

\section{REFERENCES}

Addo-Fordjour, P., Rahmad, Z.B. \& Shahrul, A.M.S. (2012) Effects of human disturbance on liana community diversity and structure in a tropical rainforest, Malaysia: implication for conservation. Journal of Plant Ecology, 5, 391-399.

Addo-Fordjour, P., Obeng, S., Addo, M.G. \& Akyeampong, S. (2009) Effects of human disturbances and plant invasion on liana community structure and relationship with trees in the Tinte Bepo forest reserve, Ghana. Forest Ecology and Management, 258, 728-734.

Addo-Fordjour, P., Rahmad, Z.B., Amui, J., Pinto, C. \& Dwomoh, M. (2013) Patterns of liana community diversity and structure in a tropical rainforest reserve, Ghana: effects of human disturbance. African Journal of Ecology, 51, 217-227.

Asner, G.P. \& Martin, R.E. (2015) Canopy chemistry expresses the life-history strategies of lianas and trees. Ecology of lianas (ed. by S. Schnitzer, F. Bongers, R.J. Burnham and F.E. Putz), pp. 299-308. Wiley, Chichester.

Bongers, F. \& Ewango, C.E.N. (2015) Dynamics of lianas in DR Congo. Ecology of lianas (ed. by S. Schnitzer, F. Bongers, R.J. Burnham and F.E. Putz), pp. 23-35. Wiley, Chichester.
Burton, M.E.H., Poulsen, J.R., Lee, M.E., Medjibe, V.P., Stewart, C.G., Venkataraman, A. \& White, L.J.T. (2016) Reducing carbon emissions from forest conversion for oil palm agriculture in Gabon. Conservation Letters, doi: 10.1111/conl.12265.

Caballe, G. (1984) The dynamics of woody lianacommunities in a rain-forest of northeast Gabon. Revue d'Ecologie la Terre et la Vie, 39, 3-35.

Caballe, G. \& Martin, A. (2001) Thirteen years of change in trees and lianas in a Gabonese rainforest. Plant Ecology, 152, 167-173.

Chave, J., Riera, B. \& Dubois, M. (2001) Estimation of biomass in a Neotropical forest of French Guiana: spatial and temporal variability. Journal of Tropical Ecology, 17, 79-96.

Chave, J., Olivier, J., Bongers, F., Chatelet, P., Forget, P.M., van der Meer, P., Norden, N., Riera, B. \& CharlesDominique, P. (2008) Above-ground biomass and productivity in a rain forest of eastern South America. Journal of Tropical Ecology, 24, 355-366.

Chittibabu, C.V. \& Parthasarathy, N. (2001) Liana diversity and host relationships in a tropical evergreen forest in the Indian Eastern Ghats. Ecological Research, 16, 519-529.

Clark, D.B. \& Clark, D.A. (1990) Distribution and effects on tree growth of lianas and woody hemiepiphytes in a Costa Rican tropical wet forest. Journal of Tropical Ecology, 6, 321-331.

Condon, M.A., Sasek, T.W. \& Strain, B.R. (1992) Allocation patterns in two tropical vines in response to increased atmospheric $\mathrm{CO}_{2}$. Functional Ecology, 6, 680-685.

Dalling, J.W., Schnitzer, S.A., Baldeck, C., Harms, K.E., John, R., Mangan, S.A., Lobo, E., Yavitt, J.B. \& Hubbell, S.P. (2012) Resource-based habitat associations in a Neotropical liana community. Journal of Ecology, 100, 1174-1182.

DeWalt, S.J. \& Chave, J. (2004) Structure and biomass of four lowland Neotropical forests. Biotropica, 36, 7-19.

DeWalt, S.J., Ickes, K., Nilus, R., Harms, K.E. \& Burslem, D.F.R.P. (2006) Liana habitat associations and community structure in a Bornean lowland tropical forest. Plant Ecology, 186, 203-216.

DeWalt, S.J., Schnitzer, S.A., Chave, J. et al. (2010) Annual rainfall and seasonality predict pan-tropical patterns of liana density and basal area. Biotropica, 42, 309-317.

DeWalt, S.J., Schnitzer, S.A., Alves, L. et al. (2015) Biogeographic patterns in liana abundance and diversity in tropical forests. Ecology of lianas (ed. by S. Schnitzer, F. Bongers, R.J. Burnham and F.E. Putz), pp. 131-146. Wiley, Chichester.

Duran, S.M., Sanchez-Azofeifa, G.A., Rios, R.S. \& Gianoli, E. (2015) The relative importance of climate, stand variables and liana abundance for carbon storage in tropical forests. Global Ecology and Biogeography, 24, 939-949.

Ewango, C.E.N. (2010) The Liana assemblage of a Congolian rainforest: diversity, structure, and dynamics, $\mathrm{PhD}$ Thesis, University of Wageningen. 
FAO/IIASA/ISRIC/ISS-CAS/JRC (2009) Harmonized World Soil Database (version 1.1). FAO, Rome, Italy and IIASA, Laxenburg, Austria.

Gentry, A.H. (1991) The distribution and evolution of climbing plants. The ecology of vines (ed. by F.E. Putz and H.A. Mooney), pp. 3-48. Cambridge University Press, Cambridge.

Getis, A. \& Ord, J.K. (2010) The analysis of spatial association by use of distance statistics. Perspectives on spatial data analysis (ed. by L. Anselin and S.J. Rey), pp. 127-145. Springer, Berlin.

Hegarty, E.E. \& Caballe, G. (1991) Distribution and abundance of vines in forest communities. The biology of vines (ed. by F.E. Putz and H.A. Mooney), pp. 313-335. Cambridge University Press, Cambridge.

van der Heijden, G.M. \& Phillips, O.L. (2008) What controls liana success in Neotropical forests? Global Ecology and Biogeography, 17, 372-383.

van der Heijden, G.M.F. \& Phillips, O.L. (2009) Liana infestation impacts tree growth in a lowland tropical moist forest. Biogeosciences, 6, 2217-2226.

Hijmans, R.J., Cameron, S.E., Parra, J.L., Jones, P.G. \& Jarvis, A. (2005) Very high resolution interpolated climate surfaces for global land areas. International Journal of Climatology, 25, 1965-1978.

Ingwell, L.L., Joseph Wright, S., Becklund, K.K., Hubbell, S.P. \& Schnitzer, S.A. (2010) The impact of lianas on 10 years of tree growth and mortality on Barro Colorado Island, Panama. Journal of Ecology, 98, 879-887.

Korner, C. \& Arnone, J.A. (1992) Responses to elevated carbon-dioxide in artificial tropical ecosystems. Science, 257, 1672-1675.

Ladwig, L.M. \& Meiners, S.J. (2009) Impacts of temperate lianas on tree growth in young deciduous forests. Forest Ecology and Management, 259, 195-200.

Laurance, W.F., Perez-Salicrup, D., Delamonica, P., Fearnside, P.M., D’angelo, S., Jerozolinski, A., Pohl, L. \& Lovejoy, T.E. (2001) Rain forest fragmentation and the structure of Amazonian liana communities. Ecology, 82, 105-116.

Laurance, W.F., Andrade, A.S., Magrach, A., Camargo, J.L.C., Valsko, J.J., Campbell, M., Fearnside, P.M., Edwards, W., Lovejoy, T.E. \& Laurance, S.G. (2014) Long-term changes in liana abundance and forest dynamics in undisturbed Amazonian forests. Ecology, 95, 1604-1611.

Ledo, A. \& Schnitzer, S.A. (2014) Disturbance and clonal reproduction determine liana distribution and maintain liana diversity in a tropical forest. Ecology, 95, 2169-2178.

Lewis, S.L., Lopez-Gonzalez, G., Sonke, B. et al. (2009) Increasing carbon storage in intact African tropical forests. Nature, 457, 1003-1006.

Lewis, S.L., Sonke, B., Sunderland, T. et al. (2013) Aboveground biomass and structure of 260 African tropical forests. Philosophical Transactions of the Royal Society B: Biological Sciences, 368, 20120295.

Madeira, B.G., Espirito-Santo, M.M., D’angelo Neto, S., Nunes, Y.R.F., Sanchez Azofeifa, G.A., Fernandes, G.W. \& Quesada, M. (2009) Changes in tree and liana communities along a successional gradient in a tropical dry forest in south-eastern Brazil. Plant Ecology, 201, 291304.

Maniatis, D. \& Mollicone, D. (2010) Options for sampling and stratification for national forest inventories to implement REDD+ under the UNFCCC. Carbon Balance and Management, 5, 9.

Marvin, D.C., Winter, K., Burnham, R.J. \& Schnitzer, S.A. (2015) No evidence that elevated $\mathrm{CO}_{2}$ gives tropical lianas an advantage over tropical trees. Global Change Biology, 21, 2055-2069.

Medjibe, V.P., Putz, F.E., Starkey, M.P., Ndouna, A.A. \& Memiaghe, H.R. (2011) Impacts of selective logging on above-ground forest biomass in the Monts de Cristal in Gabon. Forest Ecology and Management, 262, 1799 1806.

Medjibe, V.P., Putz, F.E. \& Romero, C. (2013) Certified and uncertified logging concessions compared in Gabon: changes in stand structure, tree species, and biomass. Environmental Management, 51, 524-540.

Miao, Z., Koerner, S.E., Medjibe, V.P. \& Poulsen, J.R. (2016) Wanted: new allometric equations for large lianas and African lianas. Biotropica, 48, 561-564.

Nabe-Nielsen, J. (2001) Diversity and distribution of lianas in a Neotropical rain forest, Yasuni National Park, Ecuador. Journal of Tropical Ecology, 17, 1-19.

Oslisly, R., White, L., Bentaleb, I., Favier, C., Fontugne, M., Gillet, J.F. \& Sebag, D. (2013) Climatic and cultural changes in the west Congo Basin forests over the past 5000 years. Philosophical Transactions of the Royal Society B: Biological Sciences, 368, 20120304.

Pasquini, S.C., Wright, S.J. \& Santiago, L.S. (2015) Lianas always outperform tree seedlings regardless of soil nutrients: results from a long-term fertilization experiment. Ecology, 96, 1866-1876.

Phillips, O.L., Martinez, R.V., Mendoza, A.M., Baker, T.R. \& Vargas, P.N. (2005) Large lianas as hyperdynamic elements of the tropical forest canopy. Ecology, 86, 1250-1258.

Phillips, O.L., Baker, T., Feldpausch, T.R. \& Brienen, R. (2009) RAINFOR field manual for plot establishment and remeasurement. Available at: http://www.rainfor.org/upload/ ManualsEnglish/RAINFOR_field_manual_version_June_ 2009_ENG.pdf

Putz, F.E. (1983) Liana biomass and leaf-area of a tierra firme forest in the Rio Negro basin, Venezuela. Biotropica, 15, 185-189.

Putz, F.E. (1984) The natural-history of lianas on BarroColorado Island, Panama. Ecology, 65, 1713-1724.

Putz, F.E. (1995) Relay ascension of big trees by vines in Rock Creek Park, District of Columbia. Castanea, 60, 167-169.

Putz, F.E. \& Chai, P. (1987) Ecological studies of lianas in Lambir National Park, Sarawak, Malaysia. Journal of Ecology, 75, 523-531.

Saint-Vil, J. (1977) Les climats du Gabon. Annales de l'Université National du Gabon, 1, 101-125. 
Sannier, C., McRoberts, R.E., Fichet, L.V. \& Makaga, E.M.K. (2014) Using the regression estimator with Landsat data to estimate proportion forest cover and net proportion deforestation in Gabon. Remote Sensing of Environment, 151, 138-148.

Santiago, L.S., Wright, S.J., Harms, K.E., Yavitt, J.B., Korine, C., Garcia, M.N. \& Turner, B.L. (2012) Tropical tree seedling growth responses to nitrogen, phosphorus and potassium addition. Journal of Ecology, 100, 309-316.

Schnitzer, S.A. (2005) A mechanistic explanation for global patterns of liana abundance and distribution. The American Naturalist, 166, 262-276.

Schnitzer, S.A. \& Bongers, F. (2002) The ecology of lianas and their role in forests. Trends in Ecology and Evolution, 17, 223-230.

Schnitzer, S.A. \& Bongers, F. (2011) Increasing liana abundance and biomass in tropical forests: emerging patterns and putative mechanisms. Ecology Letters, 14, 397-406.

Schnitzer, S.A., DeWalt, S.J. \& Chave, J. (2006) Censusing and measuring lianas: a quantitative comparison of the common methods. Biotropica, 38, 581-591.

Schnitzer, S.A., Mangan, S.A., Dalling, J.W., Baldeck, C.A., Hubbell, S.P., Ledo, A., Muller-Landau, H., Tobin, M.F., Aguilar, S., Brassfield, D., Hernandez, A., Lao, S., Perez, R., Valdes, O. \& Yorke, S.R. (2012) Liana abundance, diversity, and distribution on Barro Colorado Island, Panama. PLoS One, 7, e52114.

Schnitzer, S.A., Putz, F.E., Bongers, F. \& Kroening, K. (2015) The past, present, and potential future of liana ecology. Ecology of lianas (ed. by S. Schnitzer, F. Bongers, R.J. Burnham and F.E. Putz), pp. 1-10. Wiley, Chichester.

van der Sleen, P., Groenendijk, P., Vlam, M., Anten, N.P.R., Boom, A., Bongers, F., Pons, T.L., Terburg, G. \& Zuidema, P.A. (2015) No growth stimulation of tropical trees by 150 years of $\mathrm{CO}_{2}$ fertilization but water-use efficiency increased. Nature Geoscience, 8, 24-28.

Slik, J.W.F., Paoli, G., McGuire, K. et al. (2013) Large trees drive forest aboveground biomass variation in moist lowland forests across the tropics. Global Ecology and Biogeography, 22, 1261-1271.

Thomas, D., Burnham, R.J., Chuyong, G., Kenfack, D. \& Sainge, M.N. (2015) Liana abundance and diversity in Cameroon's Korup National Park. Ecology of lianas (ed. by S. Schnitzer, F. Bongers, R.J. Burnham and F.E. Putz), pp. 11-22. Wiley, Chichester.
Wright, I.J., Reich, P.B., Westoby, M. et al. (2004) The worldwide leaf economics spectrum. Nature, 428, 821-827.

Zhu, S.D. \& Cao, K.F. (2010) Contrasting cost-benefit strategy between lianas and trees in a tropical seasonal rain forest in southwestern China. Oecologia, 163, 591-599.

\section{SUPPORTING INFORMATION}

Additional supporting information may be found in the online version of this article at the publisher's web-site:

Appendix S1 Comparison of multiple regression models. Appendix S2 Results of multiple regression models for primary forest.

Figure S1 Evaluation of the effect of tree size (d.b.h.) on liana above-ground biomass (AGB) in Gabon, by fitting linear regressions of large liana AGB versus the number of trees ha ${ }^{-1}$ for four d.b.h. classes.

Figure S2 Slopes, $\beta$, of the regressions between logtransformed large liana metrics (density, BA, and AGB) and the number of trees of four size classes in the Gabon plots.

\section{DATA ACCESSIBILITY}

Data are the property of the Government of Gabon and not publicly available. Permission to access the data can be granted on an individual basis. Please contact the corresponding author for assistance in contacting the appropriate Gabonese authorities.

\section{BIOSKETCH}

John Poulsen (http://www.poulsenlabduke.com) is an ecologist with broad interests in the functioning of tropical forests and conservation of biodiversity. His research has focused on the effects of anthropogenic disturbance, such as logging and hunting, on forest structure and diversity, abundance of tropical animals and ecological processes. He has conducted most of his research in Central Africa, where he has also worked as a conservation manager, directing projects to sustainably manage natural resources in and around protected areas, and as the coordinator of government programmes to develop low emissions strategies and quantify and monitor forest carbon.

Editor: Thomas Hickler 